\title{
Experimental Investigation on Mixing and Segregation Behavior of Oxygen Carrier and Biomass Particle in Fluidized Bed
}

\author{
Botond Szücs ${ }^{1 *}$, Pál Szentannai ${ }^{1}$ \\ ${ }^{1}$ Department of Energy Engineering, Faculty of Mechanical Engineering, Budapest University of Technology and Economics, \\ H-1521 Budapest, P.O.B. 91, Hungary \\ *Corresponding author, e-mail: szucsbotond@energia.bme.hu
}

Received: 21 January 2019, Accepted: 17 April 2019, Published online: 20 May 2019

\begin{abstract}
In this work, lab-scale cold fluidization equipment is designed and constructed to investigate the mixing and segregating phenomena of binary fluidized beds. The focus of the investigation is carbon reduction with the fluidized bed technology-based Chemical Looping Combustion (CLC). Nowadays, aspiration to carbon reduction focuses on the solid fuels. Therefore, it is of great importance to integrate the benefits of CLC technology with the use of solid fuels. The measurements of fuel particles in the fluidized bed are extended from the homogeneous and spherical shape to the inhomogeneous, non-spherical shape. During the tests, an iron-based oxygen carrier (OC) for chemical looping combustors is examined with different particle sizes. In addition, the tests included the examination of three different fuel samples (crushed coal, agricultural pellet, and Solid Recovered Fuel (SRF)), which can be utilized in chemical looping combustion with In-situ gasification. The experiments are carried out using the bed-frozen method. With this method, the vertical concentration of active particles could be measured. The results show that the particle size of the oxygen carrier does fundamentally influence its vertical placement, and the non-spherical character of most alternative fuels must also be considered for optimal reactor design.

Keywords
\end{abstract}

fluidized bed, oxygen carrier, biomass, SRF, chemical looping combustion

\section{Introduction}

Nowadays the fluidized bed technology is widespread, it is applicable for low grade mixed fuel utilization. This technology can be beneficially combined with a special $\mathrm{CO}_{2}$ separation technology, the Chemical Looping Combustion, CLC [1].

To achieve sustainability in the energy industry, it is indispensable to increase the ratio of renewable energy [2-4]. The biomasses and waste-derived fuels (including Solid Recovered Fuel, SRF) have outstanding renewable potentials [5]. However, most of these solid fuels have non-spherical shapes, which may cause several problems during their utilization in the energy conversion facilities. It is also to mention that even in case of fossil fuels, their use in fluidized bed based chemical looping combustors does definitely decrease the carbon footprint of the energy industry [6]. Furthermore, if there is biomass in the fuel mix, and the whole amount of the produced $\mathrm{CO}_{2}$ can be captured, it is possible to achieve negative $\mathrm{CO}_{2}$ emission [7].
The core idea of Chemical Looping Combustion is to separate the nitrogen and oxygen from the combustion air. Two reactors are used, the air reactor and the fuel reactor, as shown in Fig. 1 [8]. Oxygen carrier (OC) is circulated between the two reactors in order to transfer oxygen from the air reactor to the fuel reactor [9].

As a consequence of this process, the exhaust gas from the air reactor is nitrogen and a few residual oxygen. Similarly, the exhaust gas from the fuel reactor is $\mathrm{CO}_{2}$ and water vapor $\left(\mathrm{H}_{2} \mathrm{O}\right)$. After condensing it, the gas will be pure $\mathrm{CO}_{2}$, which can be deposited or utilized instead of emitting into the atmosphere [10].

The greatest disadvantage of Chemical Looping Combustion is that its basic solution can apply only gaseous fuels [11]. For making it capable also for solid fuels, two main directions were elaborated, the Syngas Fueled Chemical Looping Combustion (SG-CLC) [12] and the In-situ Gasification Chemical Looping Combustion (IG-CLC) $[13,14]$. In both cases the solid fuel must be 


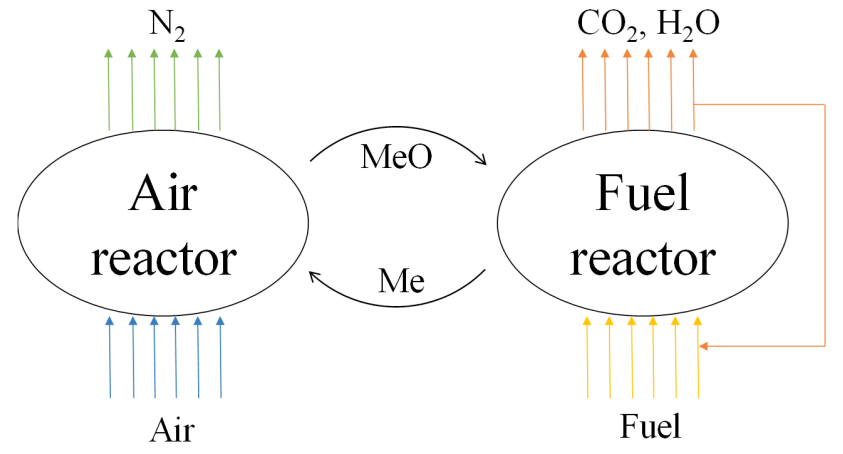

Fig. 1 Scheme of the Chemical Looping Combustion technology

gasified. In the first solution, a separate gasifier must be built to generate syngas, while in the latest one, the gasification takes place directly in the fuel reactor.

In case of the IG-CLC technique, which is one focus area of our current research, the fluidized bed fuel reactor is the scene for two processes in the same time, gasification of solids and oxidation of the gas (Fig. 2). It means that both oxygen carrier and fuel particles must be fluidized simultaneously. In some applications, a common inert bed material is used, which is sand in the most cases. Note that the mixing and segregation behavior of the currently investigated two solids (oxygen carrier and fuel) in an inert bed is of high relevance also in many other applications like Oxygen Carrier Aided Combustion (OCAC, [15]), e.g. It is also important to mention that the relevance covers both both in steady state operations and transitions between two operation modes of the technologies in question. The current investigations are useful also if the fluidization of the two classes of active particles take place in two separate reactors, of course, so for the development of SG-CLC facilities as well.

The core aim of this study is to give an answer for two still open and coherent questions regarding the utilization of solid, non-spherical fuels in Chemical Looping Combustors: on the vertical distribution of both oxygen carrier and fuel particles in the fluidized bed fuel reactor. More specifically, two different sizes of oxygen carriers were investigated, together with three typical shapes of fuel particles as spherical, cylindrical, and disc-shaped ones in a cold model at different superficial gas velocities by means of the bed frozen method.

\section{Materials and methods}

\subsection{Bed material}

A commercially available silica sand was used as the bed material throughout the experiments. It was sieved into a narrow particle interval ranging from $600-710 \mu \mathrm{m}$

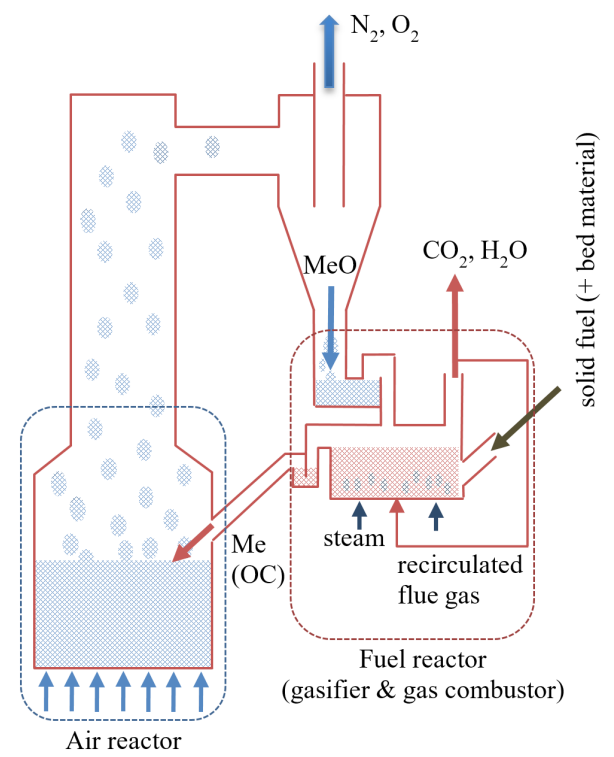

Fig. 2 The technical solution of the In-situ Gasification Chemical Looping Combustion (IG-CLC) combines the widespread fluidized bed gasification technology with the fuel reactor of an ordinary Chemical Looping Combustor (CLC)

in order to minimize its inhomogeneity. After this preparation, the particle size distribution was measured by a Horiba Particle size meter equipment, the result of which is shown in Fig. 3. Based on the same measurement, the mean diameter was determined to be $662.41 \mu \mathrm{m}$. The density of the sand was $1458 \mathrm{~kg} / \mathrm{m}^{3}$.

\subsection{Oxygen carriers}

Iron-based oxygen carriers were considered in the current study as they seem to be the most attractive ones for industrial applications due to their outstanding availability and economicalness [16]. Two sorts of iron filing were investigated, differing from each other only in their sizes. A sample of $400 \mu \mathrm{m}$ and another one of $1000 \mu \mathrm{m}$ particle

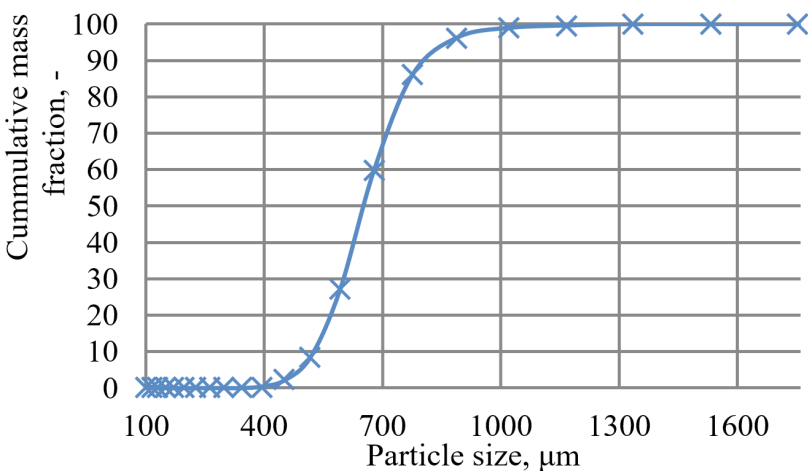

Fig. 3 Cumulative particle size distribution of the silica sand used as bed material in all current experiments. 
diameter was investigated, to be referred to hereafter as $\mathrm{OC} 1$ and $\mathrm{OC} 2$, respectively. As a preliminary characterization of these powders, their minimum fluidization velocities were measured by the commonly used method. The results of these measurements can be seen in Fig. 4, indicating about an order of magnitude difference in their minimum fluidization velocities $(0.026 \mathrm{~m} / \mathrm{s}$ and $0.19 \mathrm{~m} / \mathrm{s}$ for $\mathrm{OC} 1$ and $\mathrm{OC} 2$, respectively).

\subsection{Fuel samples}

Because the shapes of biomass particles and other waste derived fuel particles differ significantly from the sphere, the shape effect was also investigated in this study. Three different particles were investigated (Table 1), which are characterized by markedly different shapes on the one hand, and which are typical and promising candidates as IG-CLC fuels, on the other hand.

Crushed coal was considered as a basis as its shape is traditionally considered to be rather close to spherical. A Hungarian brown coal sample was used characterized by its mean particle diameter of $4.6 \mathrm{~mm}$ and $1245 \mathrm{~kg} / \mathrm{m}^{3}$ density.

Biomass pellets are typical renewable fuels, and their geometry represents another industrially relevant class.
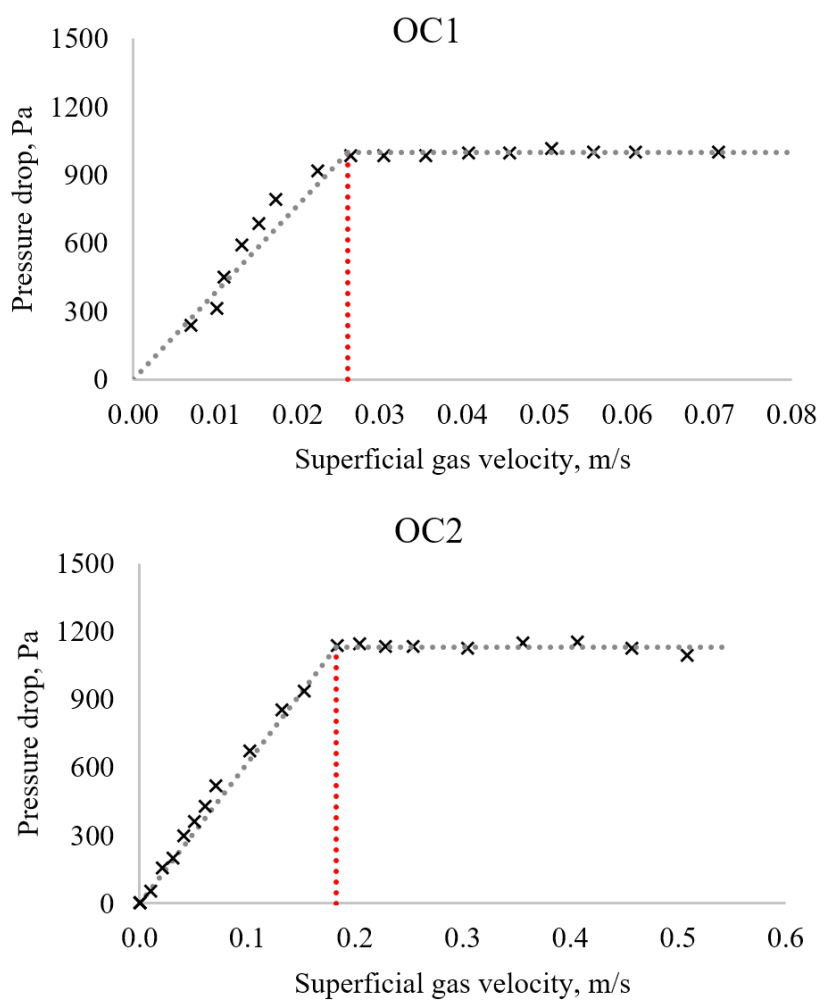

Fig. 4 Measured bed pressure drops as functions of superficial gas velocities for determining the minimum fluidization velocities of the two investigated Oxygen Carrier samples OC1 and OC2.
Table 1 Summary of biomass particle properties

\begin{tabular}{lcc}
\hline Biomass type & Size & Density $\left[\mathbf{k g} / \mathbf{m}^{3}\right]$ \\
\hline Coal & average diameter: $4 \mathrm{~mm}$ & 1700 \\
Pellet & $\begin{array}{l}\text { diameter } 6 \mathrm{~mm} \\
\text { length: } 10 \pm 5 \mathrm{~mm}\end{array}$ & 1100 \\
SRF & average diameter $4,531 \mathrm{~mm}$ & 1350 \\
\hline
\end{tabular}

Commercially available sunflower shell pellets were used of about $4 \mathrm{~mm}$ diameter, $15 \mathrm{~mm}$ typical length, and $711 \mathrm{~kg} / \mathrm{m}^{3}$ true density.

The shapes of waste-derived fuel particles are rather versatile. In order to gain industrially relevant results, real SRF samples were used from a Hungarian delivery, instead of geometrically homogeneous, synthetic particles. In spite of its complex composition, the shape of this fuel is rather close to flat, disc-like geometry, which can be considered as a third one besides the spherical and cylindrical ones described above. The waste derived fuel applied throughout the experiments is classified as a 4,2,2 SRF, according to the European standard EN 15359

\subsection{The experimental setup}

To examine the vertical distribution of several types of active particles, a lab-scale experimental equipment was designed (Fig. 5). The fluidizing air firstly goes through an inlet orifice to measure the volume flow of the air. The pressure drop on the inlet orifice can be measured by a digital manometer. A radial flow blower is responsible to ensure the necessary air volume flow. The air flow can be controlled by an inverter. For the fluidizing air distribution, a plexiglass distributor plate was used. The number of blower holes was 1160 and the ratio of the open surface was approximately $7 \%$ of the total fluidizing surface.

The riser is a plexiglass tube with $192 \mathrm{~mm}$ internal diameter. Through the transparent tube, visual observation is also feasible. The pressure drop of the bed can be measured by four pressure tapings under the distributor plate. The superficial gas velocity can be calculated from the volumetric flow and the cross section of the riser.

\subsection{The bed-frozen method}

There are several ways to observe mixing and segregation phenomena in fluidized beds like magnetic particle tracking [17], electromagnetic tracking [18], bed-frozen method [19-21]. In case of the bed-frozen method, firstly an arbitrary, stationary fluidized state should be achieved with the mixture of the examined active particles and the bed material. The stationary state can be guaranteed by ensuring an 


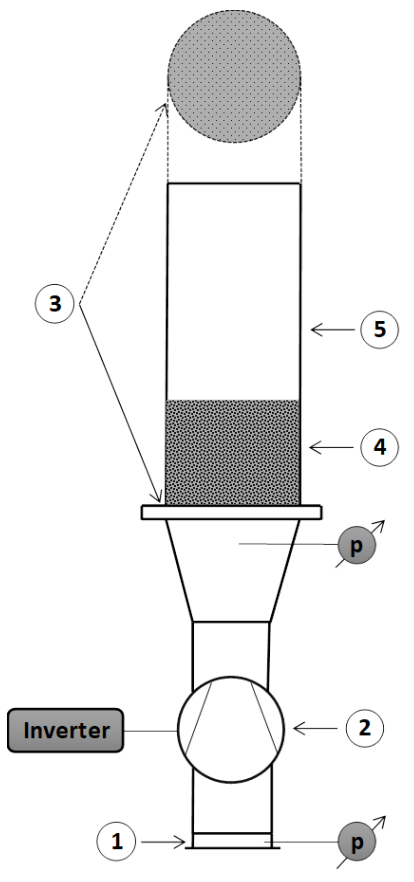

Fig. 5 The cold bubbling fluidized bed reactor. (1) inlet orifice to measure the volume flow, (2) inverter controlled radial blower, (3) air distributor (4) the examined fluidized bed, (5) riser

appropriate mixing time. For the next step, the fluidizing air is suddenly taken away. In the frozen bed the distribution of the active particles is preserved. The frozen bed can be divided into cells using separating plates [19, 22]. The amounts and concentrations of the investigated active particles (oxygen carriers and fuels) in the inert bed can then be measured by separating them from the bed material.

The entire procedure is outlined in Fig. 6 as it was carried out for the three different shaped fuels. For the two sorts of oxygen carrier, the procedure was slightly altered. The number of cells was three for investigating the fuels (with heights of 2-6-2 cm), while it was five in case of the oxygen carrier measurements $(2 \mathrm{~cm}$ high each). Additionally, a sieve was used for separating the fuels from the sand, while it could be carried out by means of a magnet in case of the much smaller but magnetizable oxygen carrier particles.

\section{Results and discussion}

In order for the results to be comparable, we used dimensionless values. The dimensionless gas velocity can be calculated as the ratio of the measured gas velocity and the minimal fluidization gas velocity of the sand. This way, 1 means the minimal fluidization velocity where the fluidization starts.

The minimal fluidization velocity derived from the fluidization curve (Fig. 7) of the bed material can be measured with the experimental equipment. To determine the dimensionless height, relative values were used as well, where 1 means a bed height equal to that of the frozen bed. The dimensionless fuel masses were derived with the same rule as before, using the ratio of the fuel mass from one cell to the mass of the full added fuel in the bed.

\subsection{The oxygen carrier distribution}

To characterize the mixing state in the fluidized bed, the well-known Nienow mixing index [20] was used according to Eq. (1):

$M=\frac{x_{t o p}}{\bar{x}}$.

If this index is above 1 , the concentration of the active particles in the top of the bed $\left(x_{\text {top }}\right)$ is higher than the average concentration in the entire bed $(x)$. Thus, $M>1$ means that the particle has flotsam nature, while $M<1$ means the opposite, that the particles have jetsam nature.

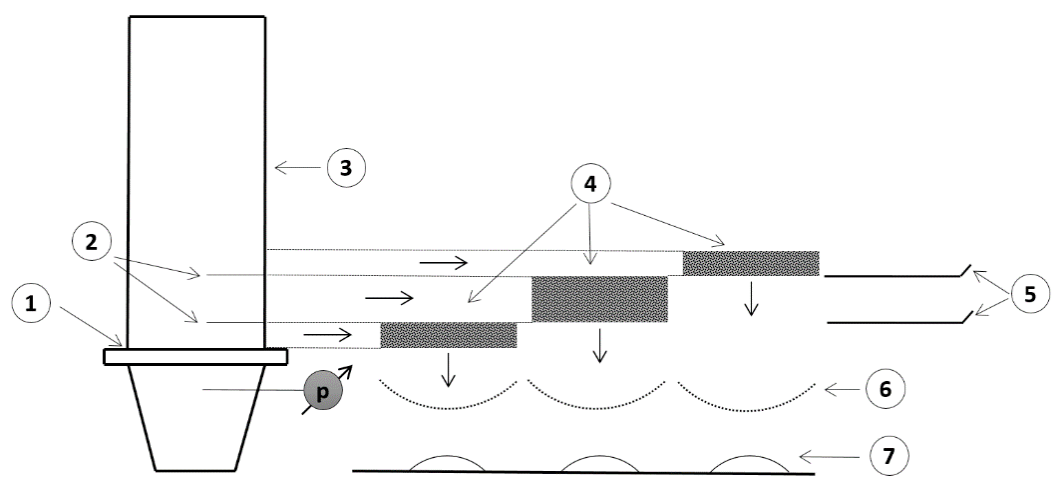

Fig. 6 Sketch of the bed-frozen method. (The details refer to its realization on the fuel particle experiments.) The frozen fluidized bed with the riser (3) is separable over the distributor plate (1) and the samples divides into three cells (4) with putting separating layers (5) into the gaps (2), then the active particles can be separated by sieving (6) from the bed material (7). 


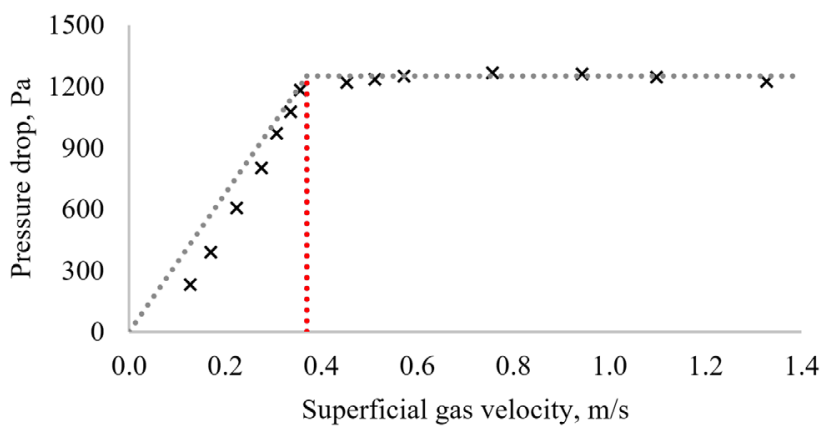

Fig. 7 The fluidization curve of the bed material. When the fluidization starts, the bed pressure drop becomes constant, independently of the fluidization gas velocity.

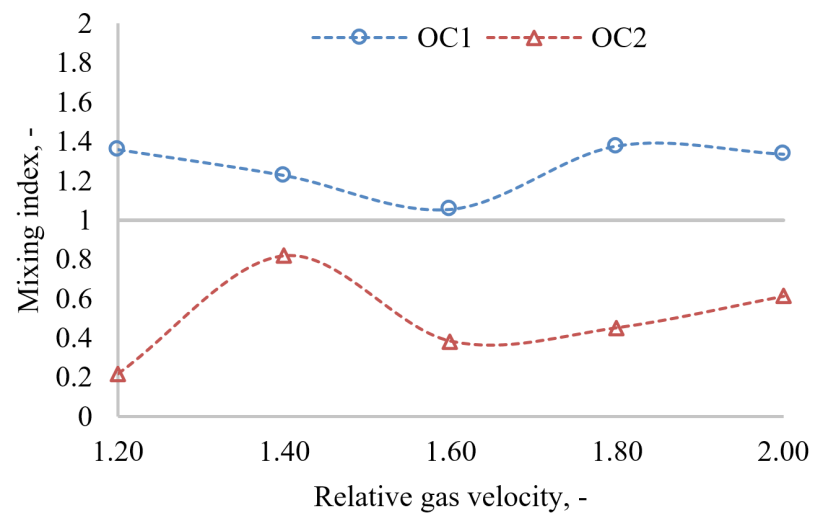

Fig. 8 Measured Nienow mixing indices (M-values of Eq. (1) of the two investigated oxygen carriers. These of $\mathrm{OC} 1(400 \mu \mathrm{m})$ are higher than 1 , in contrast to OC2 $(1000 \mu \mathrm{m})$, in which case they are lower than 1 at the whole interval.

Instead of including all the measured concentration data into this paper, just the $\mathrm{M}$ values deducted from them are shown in Fig. 8 This diagram clearly indicates the characteristic difference between the two oxygen carriers, in spite of their very similar origin and identical density. Note that although this type of measurements is always burdened by the distorting effect of the bubbles, a very clear distinguishing between $\mathrm{OC} 1$ and $\mathrm{OC} 2$ can be observed. The $\mathrm{M}$ value of $\mathrm{OC} 1$ is namely definitely and permanently above unity, while in case of OC2 this fluid-mechanical characteristic is just the opposite.

As a consequence of the above measurements, it can be stated that the distribution of the iron-based oxygen carrier depends markedly on its particle size when in the same bed material.

The finest (OC1) oxygen carrier floated to the higher part of the bed during the whole superficial gas velocity interval. This great difference between the behaviors of the two oxygen carriers was unexpected. The density of the iron is approximately 3 times larger than the density of the bed material. Because of the large density difference, both samples should have behaved as jetsam particles. Nevertheless, the Archimedes law does not solely determine the location of an active particle in a bubbling fluidized bed. In case of special circumstances, when the surface of the larger density particle is significantly smaller than the other particles, it can be a flotsam particle despite the larger density. This phenomenon is the segregation direction reversal [23]. Note that in case of the oxygen carrier, the direction of its accumulation (upwards or downwards) is a crucial issue regarding the basic design of the reactor as this type of active particle must be extracted and circulated.

\subsection{Fuel particle distribution}

Oppositely to the oxygen carrier, fuel particles should not be extracted anywhere from the reactor as they must remain there until complete consumption. Because of this, in their cases a crucial target of reactor design is their keeping in the bed body instead of allowing them to tend towards any extremes, to the top or bottom. It is also known that because of the rather heterogeneous composition of real SRF and biomass fuels, some of their particles tend to flow definitely above the bed and others sink to the bottom. As these ones get practically completely outside of the bed, their amount cannot really be characterized as concentrations, much rather as portions of the entire fuel amount in the reactor.

Because of the above considerations, the measured results are visualized in Fig. 9 as fuel masses normalized by the entire fuel mass, and their more detailed distribution inside the bed body was not further examined. According to this, the distance between the two upper lines in these diagrams indicates the ratio of the fuel found on the top, and the uppermost line is always constant one. Consequently, the distance in the middle (between the first and second lines) represents the relative amount of fuel found in the bed body, while the lowest portion (below the first line) is for the relative amount of fuel found in the bottom. The behavior of non-conventional waste based fuels as SRF deviates from the conventional spherical shape fuels. In the segregation zone, when the gas velocity is close to the minimal fluidization gas velocity, the top and the bottom cells contain considerable amounts of active particles at the same time. There is no oneway segregation as in the case of the agricultural waste pellets, because it is not only the bottom or the top cells that fill with fuel particles in the segregation zone.

The measured distribution map of crushed coal in Fig. 9 shows approximately constant function of superficial gas 

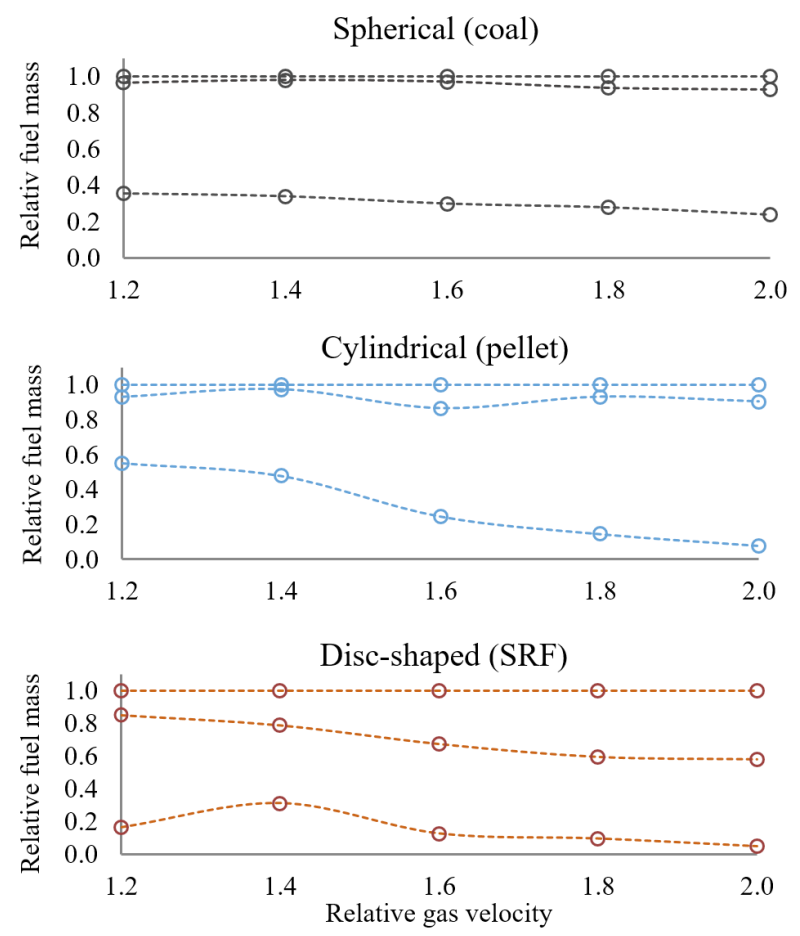

Fig. 9 Measured distribution curves of solid fuels. The distances between the curves represent the relative fuel masses in the corresponding cells: top, bed body, and bottom.

velocity. The top of the fluidized bed is actually empty. In case of high gas velocity, a small amount of active particles can be found at this position. The highest fuel amount is in the bed body. There is more fuel in the bottom of the bed in case of low superficial gas velocity, since the gas flow lifts less fuel into the bed body in this case.

The distribution curves indicate significant segregation in case of low superficial gas velocity by the cylindrical biomass pellets. The direction of the segregation is downward (similar to that of the spherical particles), which means that this fuel sample in the examined bed material behaves as jetsam. In most cases, an accumulation of the fuel in the bottom is undesirable, and it should be avoided by proper design assuring an appropriate gas velocity.

The behavior of the disc-shaped and heterogeneous SRF follows mostly that of the others, however, it seems to be more complex. The basic difference and difficulty is that there is no gas velocity, which can be optimal for keeping the majority of the fuel in the bed body. This is most probably because of the very heterogeneous composition of this fuel, including both jetsam and flotsam particles [24], and it raises the thought for operating with non-constant air velocity. All in all, the SRF particles cannot be considered as spherical objects.

\section{Conclusions}

With regards to the impact of mal-distribution of active particles in bubbling fluidized bed (BFB), the experimental part of this work was carried out with a self-developed experimental equipment. In this study, we examined the mixing and segregating phenomena of two iron based oxygen carriers and three different shaped fuel samples in bubbling fluidized bed. The distribution of the oxygen carrier particles was heavily dependent on the mean particle size. In the case of the $1000 \mu \mathrm{m}$ sample, the oxygen carrier particles behave as jetsam particles as, at low gas velocities the bottom of the bed has high active particle amount. In contrast with this, the same oxygen carrier material with significantly smaller mean particle size $(400 \mu \mathrm{m})$ has flotsam nature in the same bed material. The measured results on the fuel particles demonstrated that the distribution of crushed coal was approximately independent from the superficial gas velocity at the applied velocity interval. The bed body (middle cell) has high enough fuel concentration to maintain the advantages of the fluidized bed technology. The biomass pellet has remarkable segregation nature at low gas velocities. This problem can be solved by increasing the superficial gas velocity up to 1.8 times the minimum fluidization velocity, because in that case, the whole fuel amount is in the body of the bed. When superficial gas velocity was close to the minimal fluidization velocity, not only the bottom or the top of the bed fills with active particle, but both cells end up with high fuel concentrations. This means that the SRF contains flotsam and jetsam particles together.

\section{Acknowledgements}

This work supported by the ÚNKP-18-3-II-163 New National Excellence Program of the Ministry of Human Capacities.

This work was supported by the National Research, Development and Innovation Fund of Hungary in the frame of FIEK_16-1-2016-0007 (Higher Education and Industrial Cooperation Center) project. 


\section{References}

[1] Hossain, M. M., de Lasa, H. I. "Chemical-looping combustion (CLC) for inherent CO2 separations-a review", Chemical Engineering Science, 63(18), pp. 4433-4451, 2008. https://doi.org/10.1016/j.ces.2008.05.028

[2] Szabados, Gy., Bereczky, Á. "Economic Evaluation of Renewable Fuels through Pollutants Derived from Internal Combustion Engine", Periodica Polytechnica Mechanical Engineering, 63(1), pp. 33-38, 2018.

https://doi.org/10.3311/PPme.12521

[3] Józsa, V., Csemány, D. "Evaporation of Renewable Fuels in a Lean Premixed Prevaporized Burner", Periodica Polytechnica Mechanical Engineering, 60(2), pp. 82-88, 2016. https://doi.org/10.3311/PPme.8564

[4] Szabados, Gy., Bereczky, Á. "Comparison Tests of Diesel, Biodiesel and TBK-Biodiesel", Periodica Polytechnica Mechanical Engineering, 59(3), pp. 120-125, 2015.

https://doi.org/10.3311/PPme.7989

[5] Hamelinck, C. N., Suurs, R. A. A., Faaij, A. P. C. "International bioenergy transport costs and energy balance", Biomass and Bioenergy, 29(2), pp. 114-134, 2005.

https://doi.org/10.1016/j.biombioe.2005.04.002

[6] Anheden, M., Nasholm, A.-S., Svedberg, G. "Chemical-looping combustion - efficient conversion of chemical energy in fuels into work", In: Proceedings of the Intersociety Energy Conversion Engineering Conference, New York, USA 1995, pp. 75-81. [online] Available at: https://www.osti.gov/biblio/170397 [Accessed: 20 January 2019]

[7] Bhave, A., Taylor, R. H. S., Fennell, P., Livingston, W. R., Shah, N., Dowell, N. M., Dennis, J., Kraft, M., Pourkashanian, M., Insa, M., Jones, J., Burdett, N., Bauen, A., Beal, C., Smallbone, A., Akroyd, J. "Screening and techno-economic assessment of biomass-based power generation with CCS technologies to meet 2050 CO2 targets", Applied Energy, 190, pp. 481-489, 2017.

https://doi.org/10.1016/j.apenergy.2016.12.120

[8] Lyngfelt, A., Linderholm, C. "Chemical-looping Combustion of Solid Fuels - Technology Overview and Recent Operational Results in 100kW Unit", Energy Procedia, 63(Supplement C), pp. 98-112, 2014.

https://doi.org/10.1016/j.egypro.2014.11.011

[9] Cabello, A., Gayán, P., García-Labiano, F., de Diego, L. F., Abad, A., Adánez, J. "On the attrition evaluation of oxygen carriers in Chemical Looping Combustion", Fuel Processing Technology, 148, pp. 188-197, 2016.

https://doi.org/10.1016/j.fuproc.2016.03.004

[10] Selosse, S., Ricci, O. "Carbon capture and storage: Lessons from a storage potential and localization analysis", Applied Energy, 188, pp. 32-44, 2017.

https://doi.org/10.1016/j.apenergy.2016.11.117

[11] Mantripragada, H. C., Rubin, E. S. "Chemical Looping for Precombustion CO2 Capture - Performance and Cost Analysis", Energy Procedia, 37, pp. 618-625, 2013. https://doi.org/10.1016/j.egypro.2013.05.149

[12] Adanez, J., Abad, A., Garcia-Labiano, F., Gayan, P., de Diego, L. F. "Progress in Chemical-Looping Combustion and Reforming technologies", Progress in Energy and Combustion Science, 38(2), pp. 215-282, 2012.

https://doi.org/10.1016/j.pecs.2011.09.001
[13] Scott, S. A., Dennis, J. S., Hayhurst, A. N., Brown, T. "In situ gasification of a solid fuel and $\mathrm{CO} 2$ separation using chemical looping", AIChE Journal, 52(9), pp. 3325-3328, 2006.

https://doi.org/10.1002/aic.10942

[14] Dennis, J. S., Scott, S. A., Hayhurst, A. N. "In situ gasification of coal using steam with chemical looping: a technique for isolating $\mathrm{CO} 2$ from burning a solid fuel", Journal of the Energy Institute, 79(3), pp. 187-190, 2006. https://doi.org/10.1179/174602206X117814

[15] Hanning, M., Corcoran, A., Lind, F., Rydén, M. "Biomass ash interactions with a manganese ore used as oxygen-carrying bed material in a 12 MWth CFB boiler", Biomass and Bioenergy, 119, pp. 179-190, 2018

https://doi.org/10.1016/j.biombioe.2018.09.024

[16] Lyngfelt, A. "Oxygen Carriers for Chemical Looping Combustion - $4000 \mathrm{~h}$ of Operational Experience", Oil \& Gas Science and Technology - Revue d'IFP Energies nouvelles, 66(2), pp. 161-172, 2011.

https://doi.org/10.2516/ogst/2010038

[17] Köhler, A., Rasch, A., Pallarès, D., Johnsson, F. "Experimental characterization of axial fuel mixing in fluidized beds by magnetic particle tracking", Powder Technology, 316, pp. 492-499, 2017. https://doi.org/10.1016/j.powtec.2016.12.093

[18] Wirsum, M., Fett, F., Iwanowa, N., Lukjanow, G. "Particle mixing in bubbling fluidized beds of binary particle systems", Powder Technology, 120(1-2), pp. 63-69, 2001. https://doi.org/10.1016/S0032-5910(01)00348-5

[19] Zhang, Y., Jin, B., Zhong, W. "Experimental investigation on mixing and segregation behavior of biomass particle in fluidized bed", Chemical Engineering and Processing: Process Intensification, 48(3), pp. 745-754, 2009. https://doi.org/10.1016/j.cep.2008.09.004

[20] Nienow, A. W., Rowe, P. N., Cheung, L. Y.-L. "A quantitative analysis of the mixing of two segregating powders of different density in a gas-fluidised bed", Powder Technology, 20(1), pp. 89-97, 1978. https://doi.org/10.1016/0032-5910(78)80013-8

[21] Park, H. C., Choi, H. S. "The segregation characteristics of char in a fluidized bed with varying column shapes", Powder Technology, 246, pp. 561-571, 2013.

https://doi.org/10.1016/j.powtec.2013.06.019

[22] El-Sayed, S. A., El-baz, A. A., Noseir, E. H. "Sesame and Broad Bean Stalks: Mixing Characteristics of Chips as a Biomass Fuel for Bubbling Fluidized Bed Combustor", International Journal of Chemical Reactor Engineering, 16(6), 2018.

https://doi.org/10.1515/ijcre-2017-0138

[23] Di Renzo, A., Di Maio, F. P., Girimonte, R., Vivacqua, V. "Segregation direction reversal of gas-fluidized biomass/inert mixtures - Experiments based on Particle Segregation Model predictions", Chemical Engineering Journal, 262(Supplement C), pp. 727-736, 2015. https://doi.org/10.1016/j.cej.2014.10.028

[24] Szentannai, P., Szücs, B. "Vertical arrangement of SRF particles in a stationary fluidized bed", Powder Technology, 325, pp. 209-217, 2018. https://doi.org/10.1016/j.powtec.2017.11.015 